\title{
Water Scarcity and Food Imports: An Empirical Investigation of the 'Virtual Water' Hypothesis in the MENA Region
}

\author{
Hassan Hakimian*
}

\begin{abstract}
The suggestion that trade between nations may be explained by international differences in resource endowments is an old idea in international trade theory. Despite the long tradition established by Heckscher-Ohlin theorem and a copious literature on the so-called Leontief Paradox, economists have not, however, methodically linked MENA region's well-known water scarcity problem to its mounting food imports. Impetus has instead come from environmental and water resource specialists who have coined the term 'virtual water' to encapsulate the relationship between factor scarcity and agricultural trade in the region.

This paper first reinterprets factor endowments and comparative advantage theory in the MENA context suggesting that the 'virtual water' hypothesis is rooted in the $\mathrm{H}-\mathrm{O}$ tradition of economic thought. Virtual water is water embedded in commodities. The essential premise of this hypothesis is therefore in line with the $\mathrm{H}-\mathrm{O}$ model's tenet that 'trade in commodities is an indirect way of trade in factors of production.'

Second, we proceed to a formal testing of the ' $\mathrm{VW}$ ' hypothesis. Using comparative cross-section regression analysis for 100 countries, we test the importance of water in explaining the structure of imports for different regions of the world in general and for the MENA region in particular. Our findings appear to vindicate the VW hypothesis that water deficit areas' import structure is dominated by large food/agricultural imports. Whilst quite robust, the results are, nevertheless, sensitive to the definition of water used. This calls, inter alia, for better quality for water data measurements globally in order to improve the value and reliability of empirical studies. The study ends with a discussion of the policy and political economy implications of the hypothesis in the light of our empirical findings.
\end{abstract}

Key words: MENA water deficit; international trade theory; HeckscherOhlin model; virtual water; food and trade nexus.

JEL Classification: F10, F11, F18, Q25, N55.

\footnotetext{
*Cass Business School, City University, London; Email: H.Hakimian@city.ac.uk.
} 


\section{INTRODUCTION}

The idea that water is a critical factor of production in food and agriculture and that water deficit regions of the world should import large quantities of their food requirements is broadly an intuitive idea. In the context of the Middle East and North Africa (MENA) region's agriculture, however, this is a contentious issue. This paper probes the theoretical underpinnings of this viewpoint and provides a critical examination of its empirical content. ${ }^{1}$

Despite a long tradition established by the Heckscher-Ohlin theorem and a copious literature in international trade literature on the so-called Leontief Paradox, economists have not, however, systematically linked MENA region's well-known water constraints to its escalating food imports. Impetus has instead come from environmental and water resource specialists who have used the term 'virtual water' (VW hereafter) to capture the relationship between factor scarcity and agricultural trade in the region.

This paper comes in three parts. First, we reinterpret the theory of factor endowments and comparative advantage in the MENA context. This leads us to suggest that the VW hypothesis is indeed rooted (albeit indirectly) in the $\mathrm{H}-\mathrm{O}$ tradition of economic thought. Virtual water is water embedded in commodities. The essential premise of this hypothesis is therefore in line with the H-O model's tenet that 'trade in commodities is an indirect way of trade in factors of production.'

Second, we proceed to a formal testing of the VW hypothesis. Using comparative cross-section regression analysis for 100 countries, we test the importance of water in explaining the structure of imports for different regions of the world in general and for the MENA region in particular. Our findings vindicate the VW hypothesis: water deficit regions' import structures are dominated by large food/agricultural imports. This is particularly true of the MENA grouping of countries with large and substantial volume of food imports.

In the third and final section, we offer a discussion of the policy implications and political economy dimensions of the VW hypothesis in the light of our empirical findings.

\section{MENA'S FOOD IMPORTS AND VIRTUAL WATER}

MENA region's growing dependence on food imports from the rest of the world has attracted much attention in recent years. Fuelled by rising oil income since the 1970s and sustained by rapid population growth ever since, the region has come to rely heavily on the global trading system - principally imports from North America - to feed its population and livestock (Dyson, 1999).

Over the three decades to 2000 , the nominal food imports bill for the region rose 17 fold (growing on at an average rate of $10 \%$ per annum). Much of this growth was concentrated in the oil-boom years of the 1970s: the imports bill rose 9-fold alone in that decade (FAO data). On a per capita basis too the trend has been striking: by 1982, the 
region's expenditure on agricultural imports had shot up to $\$ 100$ per head (from $\$ 10.5$ in 1970 ) only to stabilize at around $\$ 80$ per head thereafter. Food imports have followed a similar path: per capita expenditure on imports ratcheted to about $\$ 90$ per head by the early 1980s and stabilized at about $\$ 60$ afterwards (see Figure 1). By the early 1990s, the region imported as much as one-third of its overall cereal consumption making it the largest regional importer on a global scale (Dyson, 1999: 5930). Perhaps more alarmingly, this ratio is expected to rise to an astonishing $60 \%$ by the year 2020 (PinstrupAndersen et al, 1999: 16).

The significance of agricultural and food imports is also evident in the overall structure of trade. A cursory examination of imports and exports data shows that food imports have averaged about $20 \%$ of the total merchandise imports of the region since the mid-1970s (Figure 2). Similarly, food imports have accounted for about $13 \%$ of all export proceeds of MENA countries in the three decades to 1999 (this proportion rose to a staggering one-quarter in the depth of the oil price crisis of the mid-1980s). Even by 1999 , as much as $10 \%$ of all oil-exports revenue in the Gulf region was taken up by food imports. $^{2}$

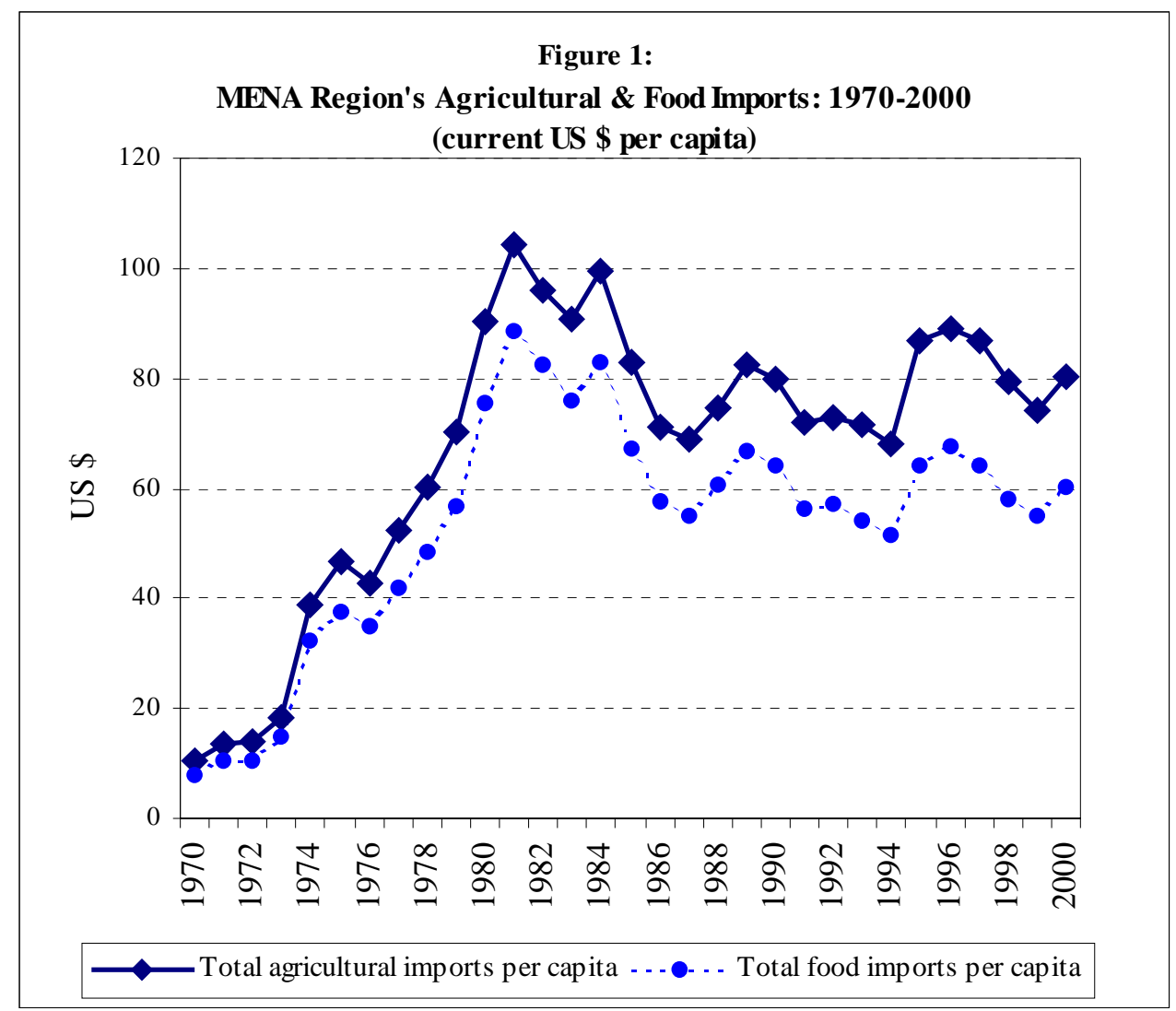

Source: FAO, Agrostat database. 
Import volumes on such a scale have inevitably caused concern and alarm among policy makers and analysts of the political economy of the region. Considerations of the economic costs of food imports have compounded 'political risks' of food dependency on the rest of the world (Richards and Waterbury, 1990: 144-45). For some, this has highlighted the irony of the MENA's 'failure' to feed its own population despite its considerable natural and mineral riches (Khaldi, 1984; Akacem, 1990). Unsurprisingly, the Middle East has been characterized as one of the least food self-sufficient regions of the world.

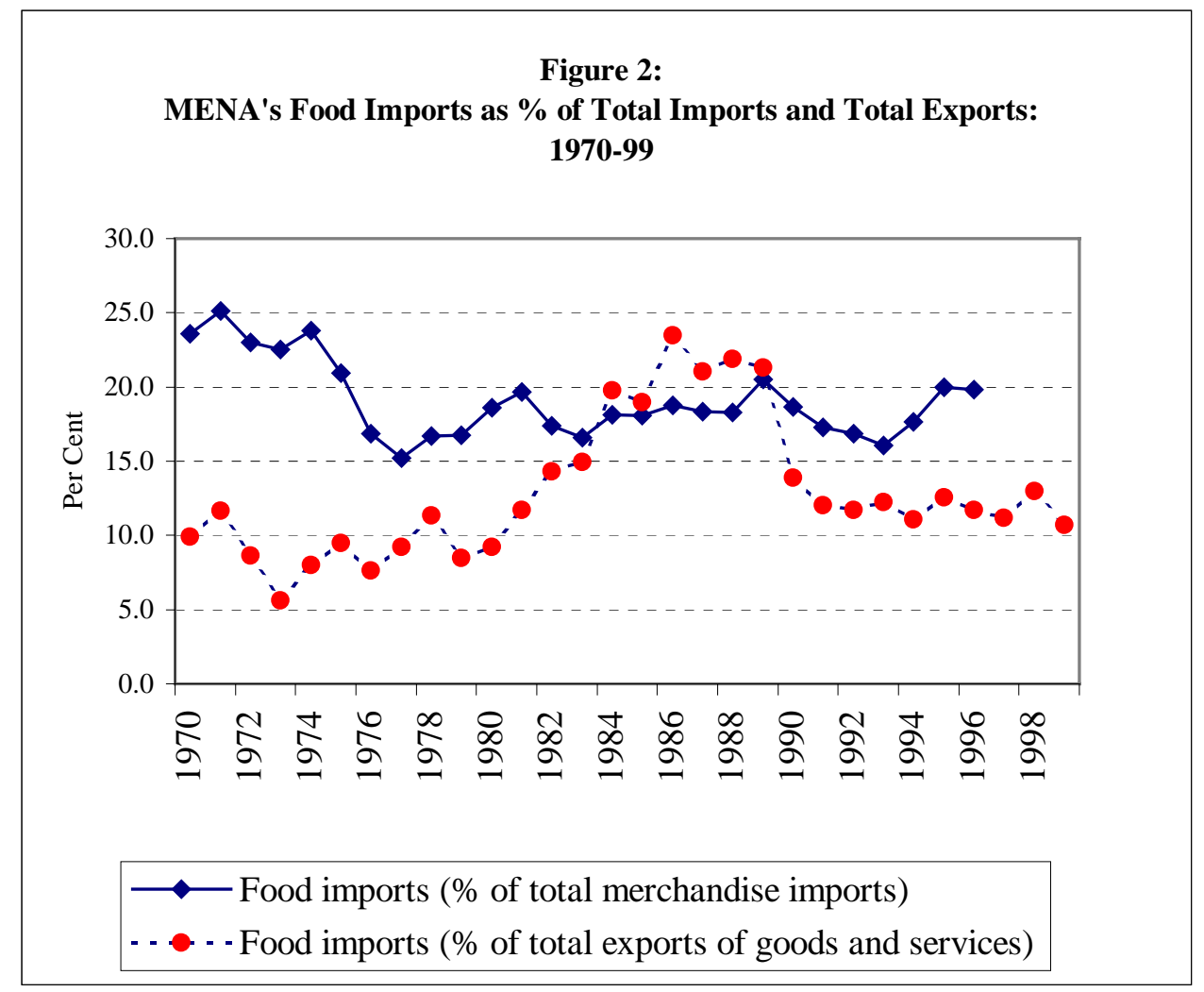

Source: World Bank (2001).

Interestingly and in sharp contrast to the above perspective, a different explanation has been offered in Tony Allan's seminal work on virtual water. According to this viewpoint, the rationale for large-scale food imports is ascribed to the natural resource endowments of the region (namely, its well-known water deficit) and the global trading system, far from posing a threat, has provided an opportunity for the region's economies to solve their serious and deteriorating water scarcity.

According to the VW hypothesis, one important indication of the scale of the water deficit of an economy is the level of its food imports. In this sense, the region ceased to have enough water to meet its food and other economic needs in about 1970 (Allan, 2001b: 5-6). However, the potential political impact of the scarcity of fresh Water in the 
Middle East has been moderated by the region's ability to reach out other 'watersheds' in the world, namely through international trade in virtual water.

Virtual water is water embedded in commodities. Wheat as a commodity that is water-intensive in production can help illustrate this concept further. For example, it requires at least 1,000 tonnes (cubic metres) of water to produce a tonne of wheat. By importing a tonne of wheat the importing economy does not have to mobilise 1,000 tonnes of water locally. On the contrary, the region manages to import 'the equivalent of the annual flow of the Nile into Egypt' through its annual wheat imports. This is how in the main 'Commodity trade moves more water into dry regions than an engineer can dream of...' (Allan, 2001a: 39). He further estimates that the volume of water involved in such transactions amounts to one-quarter of the water needs of the MENA region (2001b: 126).

Economic rationale aside, the MENA importing nations have benefited from international trade in food in several ways. The major exporters of grain - the USA and the European Union (EU) - have heavily subsidized food production costs: wheat (the main vehicle of the virtual water trade) is currently shipped only at half its production costs. Moreover, the real price of wheat has declined over the past two centuries resulting in exceptionally 'favourable' supply side conditions for the food deficit countries of the MENA region.

Moreover, for Allan the VW 'solution' has played an effective role in softening and even deferring the political impact of water scarcity. The fact that the much-predicted regional conflicts over water have not materialized is in large part a tribute to the global trade in virtual water. Despite this, the VW solution remains outside the 'sanctioned discourses' of food and water in the MENA region: to officially acknowledge it will be politically unacceptable as admitting water deficit is the same as an 'admission of the problem' itself (2001b: 164-5).

Although Allan does not formally articulate his argument in terms of international trade theory, it is clear that he sees in global trading system in commodities an exceptional opportunity (or a comparative advantage) for water deficit countries of the MENA region to alleviate their pressing food and commodity needs.

In the next section, we suggest the VW hypothesis can in fact be interpreted as an application of the well-known Heckscher-Ohlin Theorem of international trade with the MENA as the regional, and food (or cereal) production as the sectoral, context for such an interpretation.

\section{FACTOR ABUNDANCE AND COMPARATIVE ADVANTAGE: OLD THEORY - NEW INTERPRETATION?}

That trade between nations may be explained by international differences in resource endowments (rather than production technologies) is an old idea in international trade theory. Developed as an extension of the Ricardian concept of comparative advantage, the so-called Heckscher-Ohlin (H-O) theorem has had wide currency in explanations of inter- 
industry trade between nations. Focusing on resource endowments and factor-intensities of production, it is perhaps surprising that this long-established theorem has not yet been directly applied to the water-resource requirements of food production in arid and semiarid MENA type economies.

The H-O model is based on two essential premises: (i) that countries vary from each other in terms of their productive resources (inputs such as labour, capital and natural resources); and (ii) that goods are produced using different proportions of those resources. In a 2x2x2 framework (two countries, two inputs and two goods), the model predicts that each country will export (import) the good which uses its abundant (scarce) factor intensively. A standard interpretation of the model in the context of bilateral North-South trade implies, therefore, that a country such as India (well-endowed in labour resources) will export textiles (a labour-intensive product) to another country like Canada, which has abundant supplies of capital, in return for imports of (capital-intensive) products such as automobiles.

Despite its analytical elegance and the forthrightness of its predictions, empirical investigations of the model have at best met with mixed success. Initially, considerable efforts were devoted to resolving the so-called 'Leontief Paradox' (i.e., why an advanced industrial country like the USA with abundant capital resources should seemingly import capital-intensive products). ${ }^{3}$ This led to a voluminous literature and with it perhaps one of the best-known empirical curiosities of modern times in economics. While most efforts at resolving the Leontief Paradox focused on bilateral type trade (e.g., USA's trade with the rest of the world), other attempts focused on extending the model to take account of multi-factor, multi-good and multi-country trading situations. This in turn led to a more careful and elaborate view of the factor content of foreign trade and the importance of considering other factors (than resource endowments) in explanations of trade (e.g., economies of scale, trade policies and demand factors; see Bowen et al, 1987; Krueger, 1977; Harkness, 1978 for extensions and empirical tests; also Lawler and Seddighi, 2001, and Krugman and Obstfeld, 1991, for an exposition of the H-O model and a good review of the empirical tests).

Despite the H-O model's less than happy encounter with empirical reality, there is, nevertheless, general consensus that it remains a useful 'broad-brush' explanation of some major features of the pattern of trade. This is highlighted in recent adaptations of the model to explain the structure and pattern of regional inter-industry trade. Wood and Mayer (2001), for instance, have argued that Africa's concentration of unprocessed primary products is due largely to this region's combination of low skill labour force and abundant land. Likewise, using the same framework they have ascribed South Asia's specialisation in exports of labour-intensive manufactures to its low level of education and scarcity of natural resources compared to its abundant supply of labour (Mayer and Wood, 1999).

The Wood and Mayer framework avoids some of the intricacies and stringent assumptions of the $\mathrm{H}-\mathrm{O}$ model by focusing on key factor intensities in production (principally land/labour and skill/labour). The result is identification of interesting and useful patterns of inter-industry trade in a broad regional context. In the next section, we 
adapt this framework and apply it to account for MENA's food imports and water resources.

One of the original appeals of the $\mathrm{H}-\mathrm{O}$ model is that it views trade in goods essentially as an indirect way of trading factors of production. With this interpretation, the application of the model to MENA water resources context yields strikingly similar results to that of the $\mathrm{VW}$ hypothesis. Bearing in mind that production of food and agricultural output is most water intensive (compared to manufacturing, for instance; see Section 2 above), and taking account of the well-known water scarcity of the MENA region, both $\mathrm{H}-\mathrm{O}$ model and the VW hypothesis would predict a specialization pattern that is based on imports of food and agricultural products from the water abundant countries of the EU and USA.

Despite its obvious relevance to the MENA region's food and agricultural scene as well as the well-known properties of the H-O model in international trade, there has as yet been no connection made between these two approaches. Moreover, the VW hypothesis too remains largely untested to date. ${ }^{4}$

In what follows, we proceed to testing this hypothesis using cross-section data for 100 countries. After specifying the model and discussing data sources and measurements, the regression results are presented and discussed in the next section.

\section{THE MODEL}

Since the focus of the study is the determinants of food and agricultural imports, we proceed with an imports equation that explains variations in the share of food and agriculture in the imports of different countries as a consequence of their relative supplies of water, labour and land. Informed both by the $\mathrm{H}-\mathrm{O}$ model and the $\mathrm{VW}$ hypothesis, we would expect water deficit countries to rely more heavily on food imports. This is because they would have a comparative disadvantage in the production of water-intensive products (cereals are prime examples in this respect). The notion of scarcity (or abundance) of factors used here is a relative one and is defined as a ratio of water and labour to land. A cross-country regression equation is used to study this relationship:

$$
\left(\frac{M a g f}{M m f g}\right)_{i}=\alpha+\beta\left(\frac{W}{N}\right)_{i}+\delta\left(\frac{L}{N}\right)_{i}+\lambda R_{i}+\mu_{i}
$$

where $\mathrm{M}_{\mathrm{agf}}$ and $\mathrm{M}_{\mathrm{mfg}}$ are imports of 'agricultural and food products' and 'manufactured goods' respectively for country $i ;\left(\frac{W}{N}\right)_{i}$ is water/land ratio land; $\left(\frac{L}{N}\right)_{i}$ is labour/land ratio; $R_{i}$ is the percentage of irrigated land in the total cropland (irrigated land as a percentage of $\mathrm{N}$ ) and $\mu_{i}$ is a random error term subject to the usual assumptions in the Classical Linear Regression Model (CLRM). All variables are expressed in logarithmic forms in all our estimations. 
A simpler version of the model may be specified as follows:

$$
\left(\frac{M a g f}{M m f g}\right)_{i}=\alpha+\beta\left(\frac{W}{L}\right)_{i}+\lambda R_{i}+\mu_{i}
$$

Here, water endowment per head $\left(\frac{W}{L}\right)$ i appears as the independent variable relating labour/land and water/land variables. It should be noted, however, that this version assumes water/land and labour/land ratios (intensities) in production are the same across different countries (as land is cancelled out). This may or may not be acceptable from a production point of view. We will, however, test both versions.

\subsection{Data and Resource Measurements}

Cross section data from 100 countries are used for estimation purposes. These include 14 countries in the MENA region; 20 in Africa; 18 in Latin America and the Caribbean; 10 in South and Southeast Asia; 18 in Eastern Europe and Central Asia; and 20 in the Developed world (see Annex A for a full list of these countries). Unless otherwise specified, all data used are for 1997 (the latest year for which data were available) and are expressed as 3-year averages to smooth out annual variations.

The trade data come from UNCTAD's Comtrade database. We have used 2 digit Standard International Trade Classification (SITC) to define sectors (see Table 1). We differentiate imports of 'food and agriculture' in three ways: food imports $(M f d)$; cereals imports (Mcer); and imports of food and agriculture combined (Magf). The share of these imports are in turn are worked out in three ways: in relation to (a) total imports (Mtot); (b) 'non-agricultural' imports (Mnagf; these consist of manufacturing and mineral imports); and (c) manufacturing imports $(M m f g)$.

Water data used in our study are from the authoritative World Resources 2000-2001 database (World Resources Institute, 2000). While this is possibly the best dataset available, it should, nevertheless, be pointed out that there is considerable variation in the quality of water data for different countries. For instance, figures available are based on disparate sources and dates. They have been used as indicative of the water endowment in the countries concerned in 1997 on the assumption that water resources in the short-term are relatively stable (inter-annual and long-term variations can, of course, be substantial; see World Resources Institute, 2000). The main water indicator used in this paper is 'annual water withdrawals' (denoted by W). However, to test for data measurement and definitional sensitivity, we have also conducted tests on the basis of alternative concepts of water, namely 'internal renewable water resources' and 'annual water withdrawals attributable to agriculture'. 
Both land and labour data are extracted from World Development Indicators (World Bank, 2001). Land is measured as 'total arable land' (denoted by N) and labour refers to 'total population' in each country (denoted by L). Again, for both land and labour, we have tested for alternative measurements ('total landmass' for land; and 'total adult population in the age group 15-64' as well as 'total labour force' for labour). In this way, we are able to conduct a sensitivity analysis of our findings for the alternative resource definitions used. Results are presented in Table 1 and discussed in the next section.

\subsection{Regression Results}

Table 1 provides a summary of the regression results for a sample of 100 countries using data for 1997. The results are presented first in three groupings of three equations testing the comparative advantage theory as in equation 1 above (see lines 1-9). These are followed by the results of the simpler version (equation 2), which are reported in line 10. Finally, total import values (rather than import structures) are used as the dependent variables in lines 11-13. These latter equations incorporate further a population variable as a proxy for country size. The inclusion of population variable in these is on the expectation that import needs will be partly a reflection of resource endowments and partly of population size (number of 'mouths to feed'). By using three alternative definitions of agriculture and three definitions of 'other' sectors to discuss the structure of imports (see above), we ensure our sectoral definitions are not defined too narrowly. This also allows us to conduct a sensitivity analysis for the definition of sectors adopted and hence test the comparative advantage theory in several ways. All variables are expressed in $\log$ format and all coefficients are OLS estimators. T-ratios for these estimates are given in brackets and results of heteroskedasticity tests are also reported in the notes to the table.

This Table shows robust and highly significant coefficients (in most cases at 1\%) for water (expressed as a ratio of land) with a negative sign in support of the VW hypothesis (i.e., water scarce economies are associated with greater 'agricultural/food' imports relative to other imports). What is particularly interesting is that the VW hypothesis appears strongest when applied to cereals (reported in lines 1-3). This is not unexpected since we know that cereals are relatively water-intensive in production.

The simpler version of the VW hypothesis (regression 10) also shows a very strong and also highly significant coefficient for water with a negative sign. This too appears to vindicate the importance of water (per head of population in this instance, $\left(\frac{W}{N}\right)$ ) as a determining factor in the structure of cereal imports.

Lines 1-10 also show that in both versions of the equation, the other two key variables of labour per land $\left(\frac{L}{N}\right)$ and irrigation (R) have highly significant and positive coefficients. The former indicates population density and hence a positive association with food imports is intuitive. This can, for instance, be explained in terms of diminishing 
returns to agriculture in intensive farming and hence the greater reliance on imports for countries with higher population density.

Irrigation's connection with food/agricultural imports, however, is less self-evident. On one hand, greater irrigation facilities may reduce imports since irrigated agriculture is widely associated with both higher and less variable yields. Furthermore, to the extent that irrigation infrastructure may be viewed as substitution of capital for water and labour in agriculture, this may indicate an expected reduction in imports. On the contrary, irrigation may be positively associated with food imports (as implied by our regression results) if it is a symptom of food deficit. This is for instance the case of typical MENA countries with high food imports (such as Egypt with a 100\% reliance on irrigation; and for the smaller and dry GCC states in the range of 70\%-95\%). Irrigation investment in these cases is at least partly indicative of the water deficit itself and the need for large quantities of food imports.

In all regressions reported in lines 1-10, the independent variables account for between one-third and one-half of the total variations in the dependent variables (see the two columns for R-squared and adjusted values). The unexplained part must be due to other factors such as government policies, the extent and form of foreign aid, the degree of industrialization, transport costs, etc; hence the contention in Section 3 above that even if relevant, resource endowments in the $\mathrm{H}-\mathrm{O}$ framework cannot explain all variations in the patterns of international trade. ${ }^{6}$

We can also see that the dummy variable for the MENA region also has a significant and positive sign in these equations. This indicates that the MENA group stands out among other regions in respect of the behaviour of their food structure. The specificity of MENA may for instance be due to unaccounted factors in the model such as their oil income, the political economy of food subsidies favouring cheap imports for the benefit of urban consumers, more volatile climates, etc. In general, it also appears that the MENA dummy for cereals is largest and more significant than in other equations. For space limitations, other regional dummies are not reported in Table 1, but it should be pointed out that like MENA, Africa's dummy variable too is consistently significant in all regressions suggesting that this continent too may have similar determinants of its imports structure as the MENA (see below).

This is further supported by Figures 3, which shows the scatter diagram of imports structure (log of Mcer/Mmfg) and water endowments (log of water endowment per head of adult population) for all 100 countries with the MENA observations highlighted specifically. It can be seen that with the exception of Israel and Turkey (both exporters of manufactured goods and with more diversified economies), more or less, other MENA observations appear above the trend line. ${ }^{7}$ For all other MENA countries in the sample, the diagram indicates a greater than proportionate prevalence of cereals in their imports structure.

Moreover, regressions 11-13 focus on the determinants of total volumes of agricultural imports (rather than their structures). Here, water/land ratio is expectedly less of a determining factor but labour/land ratio and population are far more important. 
Population in particular is the single most important independent variable in this context (R-squared is over $78 \%$ for all three versions of cereals, food and agriculture and food combined). ${ }^{8}$

Last, but not least, we conducted sensitivity analysis for alternative definitions and measurements of the three independent variables of labour, land and water. For labour and land, the results were robust almost regardless of the definitions adopted (see section 4.1 above and notes for Tables 1). However, results proved to be highly sensitive to the water definition adopted. The reported results in Table 1 are based on water defined as 'annual water withdrawals' as mentioned previously. In fact, the other two alternative measurements ('internal renewable water resources' and 'annual water withdrawals attributable to agriculture') behaved very badly in all equations used here and are not therefore reported in the Table.

This would appear to suggest that: (a) care must be taken when interpreting the results as these depend critically on the measurement of water; and (b) there must be concerted effort to improve the quality of data on water (see Allan, 2000b for a strong case for including unreported soil water in international water statistics).

\section{DISCUSSION AND CONCLUSIONS}

In this paper, we have first reinterpreted the $\mathrm{H}-\mathrm{O}$ model of international trade in the MENA context to take account of its water scarcity and food imports. We have shown that the so-called virtual water hypothesis is strikingly close in substance to this longestablished tradition in international trade theory.

Second, our empirical results provide a broad vindication of the main tenets of the VW approach suggesting that at least in the context of arid and semi-arid countries such as those in the Middle East and North Africa, food imports are the logical and rational outcome of a specialisation pattern, which is based on comparative advantage rather indicating 'agricultural failure.' While broadly correct, at least two qualifications apply to this conclusion: one relating to the concept and measurement of water, another to the nature of trade policy.

First, as stated above, although robust, the results were found to be highly sensitive to the definition and measurement of water used. In this respect, we must avoid making generalized policy conclusions based on a narrow understanding of a key variable such as water. The overarching conclusion, if any, should in fact be to call for more research in this field in order to improve the quality of global data on water available. This may require, inter alia, consistent, reliable and comprehensive data to include possibly also water in the soil profiles of different countries and regions of the world.

A second and more general qualification applies to the political economy of trade policy. The question arising here is to what extent trade (and development) policy should be based on static comparative advantage considerations. This is a vexed issue over which there is equally a long tradition of debate and controversy. The free trade tradition of thought in economics is viewed by some suspicion partly because in the words of Joan 
Robinson 'free trade is the ideology of strong nations.' (1964). In recent years, the tenets of the so-called Washington consensus in the trade policy area too have been called to question at least in the context of the Asian countries. For instance, it has been argued that, far from free trade, in fact, interventionist and targeted state policies to 'get prices wrong' were key to redefining comparative advantage patterns in the course of East Asian industrialization (see Amsden, 1989; Wade, 1990).

Whether MENA countries should limit their options to pursuing a narrow and static version of the comparative advantage theory is an issue that should not be taken for granted. It merits a full debate, which is unfortunately beyond the scope of this paper. Whether they have the institutional capability or political willingness to develop new comparative advantages in a dynamic context is another issue. Hopefully, the research in this paper can encourage a lively and better-informed discussion - a discussion about the significance of food in trade policy in the MENA region as well as the importance of water as a hitherto-neglected but key resource endowment in shaping international trade and specialization patterns among a wider range of countries. 


\section{References}

Akacem, M (1990), 'The Cost of Arab Food Imports,' ch. 11 in Adel Salman (ed., 1990), Agriculture in the Middle East - Challenges\& Prospects, New York: Paragon House.

Allan, J A (1996), 'The Political Economy of Water [In The Jordan Basin]: Reasons for Optimism but Long Term Caution,' in Allan, J A and J H O Court, Water, Peace and The Middle East: Negotiating Resources in The Jordan Basin, London: Tauris Academic Studies, pp. 75-120.

Allan, J A (2001a), 'Virtual Water - Economically Invisible and Politically Silent - A Way to Solve Strategic Water Problems,' International Water \& Irrigation, vol. 21, no. 4, pp. 39-41.

Allan, J A (2001b), The Middle East Water Question: Hydropolitics and The Global Economy, London: I. B. Tauris.

Amsden A H (1989), Asia's Next Giant: South Korea And Late Industrialization, Oxford: Oxford University Press.

Bowen, Harry P, Leamer, Edward E and Leo Sveikauskas (1987), 'Multicountry, Multifactor Tests of The Factor Abundance Theorem,' The American Economic Review, vol. 77, Issue 5, December, pp. 791-809.

Dyson, T (1999), 'World food Trends and Prospects to 2025,' Proceedings of the National Academy of Sciences USA,' Colloquium Paper, vol. 96, May, pp. 5929-36.

Earle, Anton (2001), 'The Role of Virtual Water in Food Security in Southern Africa,' SOAS Water Issues Study Group, Occasional Paper no 33, available from http://www2.soas.ac.uk/Geography/waterissues/OccasionalPapers/AcrobatFiles/OC C33.pdf.

FAO, Food and Agriculture Organization of the UN, Agrostat database.

Harkness, J P (1978), 'Factor Abundance and Comparative Advantage,' The American Economic Review, vol. 68, December, pp. 784-800.

Khaldi, N (1984), 'Evolving Food Gaps in the Middle East/North Africa: Prospects and Policy Implications,' Research Report, no. 47, Washington DC: IFPRI.

Krueger, A O (1977), Liberalization Attempts and Consequences, Cambridge, Massachusetts: Ballinger Publishing Co.

Krugman P R and M Obstfeld (1991), International Economics - Theory and Policy, second edition, New York: HarperCollins Publishers.

Lawler, K and H Seddighi (2001), International Economics - Theories, Themes and Debates, London and New York: Prentice Hall. 
Leontief, W (1953), 'Domestic Production and Foreign Trade: the American Capital Position Re-examined,' Proceedings of the American Philosophical Society, vol. 97, pp. 331-49.

Pinstrup-Andersen, P, Pandya-Lorch, R and M W Rosegrant (1999), World food Prospects: Critical Issues for the Twenty-First Century, 2020 Food Policy Report, Washington DC: IFPRI.

Richards, A and J Waterbury (1990), A Political Economy of the Middle East, Boulder, CO: Westview Press.

Robinson, J (1964), Economic Philosophy, An Essay on the Progress of Economic Thought, Harmondsworth : Penguin.

Wade, R (1990), Governing The Market: Economic Theory and the Role of Government in East Asian Industrialization, Princeton, N J: Princeton UP.

Wood A and J Mayer (2001), 'Africa's Export Structure in A Comparative Context,' Cambridge Journal of Economics, vol. 25, pp. 369-94.

Wood A and J Mayer (1999), 'South Asia's Export Structure in A Comparative Perspective,' IDS Working Paper 91, Brighton: Institute of Development Studies.

World Bank (2001), World Development Indicators, CD ROM, Washington, DC.

World Resources Institute (2000), World Resources 2000-2001, CD ROM, Washington, DC. 


\section{Appendix A: Country Coverage}

The total number of countries included in the sample is 100 . These are listed below in relevant groupings as follows:

\section{Africa (20)}

Cameroon, Central African Republic, Chad, Republic of Congo, Cote d'Ivoire, Ethiopia, Gabon, Kenya, Madagascar, Malawi, Mauritius, Mozambique, Nigeria, Senegal, South Africa, Sudan, Tanzania, Uganda, Zambia, Zimbabwe.

\section{Latin America (18)}

Argentina, Bolivia, Brazil, Chile, Colombia, Costa Rica, Ecuador, El Salvador, Guatemala, Honduras, Jamaica, Mexico, Nicaragua, Panama, Paraguay, Peru, Uruguay, Venezuela.

\section{MENA (14)}

Algeria, Bahrain, Egypt, Israel, Jordan, Kuwait, Libya, Morocco, Oman, Saudi Arabia, Syria, Tunisia, Turkey, Yemen.

\section{South Asia (4)}

Bangladesh, India, Nepal, Pakistan.

\section{East Asia (6)}

China, Indonesia, Korea (Republic), Malaysia, Philippines, Thailand.

\section{Eastern Europe \& Central Asia (18)}

Albania, Armenia, Bulgaria, Croatia, Czech Republic, Estonia, Hungary, Kyrgyzstan, Latvia, Lithuania, Moldova, Mongolia, Poland, Romania, The Russian Federation, Slovakia, Slovenia, Turkmenistan.

\section{Developed Countries (20)}

Australia, Austria, Canada, Denmark, Finland, France, Germany, Greece, Ireland, Italy, Japan, Netherlands, New Zealand, Norway, Portugal, Spain, Sweden, Switzerland, United Kingdom, United States. 


\begin{tabular}{|c|c|c|c|c|c|c|c|c|c|c|c|}
\hline \multirow{2}{*}{\multicolumn{2}{|c|}{$\begin{array}{l}\text { Dependent } \\
\text { Variable } \\
\end{array}$}} & \multirow[b]{2}{*}{ Constant } & \multicolumn{6}{|c|}{ Coefficients on Independent Variables } & \multirow[b]{2}{*}{ n } & \multirow[b]{2}{*}{$\mathbf{R}^{2}$} & \multirow[b]{2}{*}{$\begin{array}{c}\text { Adjusted } \\
\mathbf{R}^{\mathbf{2}} \\
\end{array}$} \\
\hline & & & $\mathbf{L} / \mathbf{N}$ & W/N & W/L & $\mathbf{R}$ & $\mathbf{P}$ & Dummy ME & & & \\
\hline & Mcer/Mmfg & $-2.66(-7.70)$ & $0.28(2.17)$ & $-0.33(-2.59)$ & - & $0.35(3.76)$ & - & $0.58(4.15)$ & 95 & 0.50 & 0.47 \\
\hline 2 & Mcer/Mnag & $-2.71(-7.97)$ & $0.26(2.12)$ & $-0.34(-2.65)$ & - & $0.34(3.62)$ & - & $0.58(4.23)$ & 95 & 0.50 & 0.44 \\
\hline 3 & Mcer/Mtot & $-2.70(-8.49)$ & $0.24(2.04)$ & $-0.30(-2.55)$ & - & $0.31(3.56)$ & - & $0.55(4.3)$ & 95 & 0.51 & 0.45 \\
\hline 4 & $\mathrm{Mfd} / \mathrm{Mmfg}$ & $-1.52(-7.17)$ & $0.24(3.06)$ & $-0.23(-2.97)$ & - & $0.20(3.41)$ & - & $0.17(1.94)$ & 95 & 0.41 & 0.34 \\
\hline 5 & Mfd/Mnag & $-1.58(-7.67)$ & $0.23(3.02)$ & $-0.24(3.10)$ & - & $0.18(3.22)$ & - & $0.17(2.05)$ & 95 & 0.39 & 0.32 \\
\hline 6 & Mfd/Mtot & $-1.57(-8.73)$ & $0.20(3.07)$ & $-0.20(-3.04)$ & - & $0.15(3.12)$ & - & 0.14 (1.93) & 95 & 0.39 & 0.33 \\
\hline 7 & Magf/Mmfg & $-1.28(-7.41)$ & $0.19(3.09)$ & $-0.21 \quad(-3.31)$ & - & $0.17(3.75)$ & - & $0.15(2.11)$ & 95 & 0.38 & 0.32 \\
\hline 8 & Magf/Mnag & $-1.34(-8.27)$ & $0.19(3.12)$ & $-0.22(-3.59)$ & - & $0.16(3.62)$ & - & $0.15(2.31)$ & 95 & 0.37 & 0.30 \\
\hline 9 & Magf/Mtot & $-1.33(-9.92)$ & $0.16(3.25)$ & $-0.18 \quad(-3.65)$ & - & $0.13(3.62)$ & - & $0.12(2.23)$ & 95 & 0.37 & 0.30 \\
\hline & Mcer/Mmfg & $-2.62(-7.75)$ & - & - & $-0.30(-2.61)$ & 0.33 & - & $0.57(4.13)$ & 95 & 0.50 & 0.46 \\
\hline & Mcer & $1.0(1.87)$ & $0.26(2.46)$ & $0.04(0.46)$ & - & - & $0.67(11.01)$ & $-0.27(-2.44)$ & 0.78 & 99 & 0.76 \\
\hline 12 & Mfd & $1.85(3.51)$ & $0.31 \quad(2.95)$ & $-0.02(0.31)$ & - & - & $0.67(11.21)$ & $-0.74(-6.78)$ & 0.84 & 99 & 0.82 \\
\hline & Magf & $1.72(2.88)$ & $0.31(3.45)$ & $-0.04(-0.48)$ & - & - & 0.7 (10.7) & $-0.77(-8.32)$ & 0.85 & 99 & 0.83 \\
\hline
\end{tabular}


1. All variables are in log forms and coefficients are OLS estimators. Results were produced using EViews Version 3.1

2. M refers to imports for all dependent variables. Sectors are defined as follows: Cereals (cer); Food (fd); agriculture and food (agf); manufacturing (mfg); non-agricultural (nag); and total (tot). They are based on 2 digit Standard International Trade Classification (SITC) given in UNCTAD's Comtrade database.

3. Water (W) is defined as 'annual water withdrawals.' Alternative measurements behaved badly (see discussion in the text).

4. Test results proved insensitive to different definitions of labour: the 'total population', 'adult population' (aged 15-64) and 'total labour force'. In lines 1-10 these are reported for $\mathrm{L}=$ total population and in lines 11-13 as $\mathrm{L}=$ adult population.

5. Land (N) refers to all cropland. Results proved insensitive to the alternative definition of land as 'total landmass.'

6. Irrigation $(\mathrm{R})$ is percentage of cropland irrigated.

7. (P) refers to total population.

8. All equations were tested for prevalence of heteroskedasticity using White's Heteroskedasticity Test. In the case of equations 1-12 heteroskedasticity was ruled out at less than 5\% significance level. In the case of equation 13, however, the t-ratios reported are based on White's Heteroskedasticity-Consistent Standard Errors.

9. The overall significance of all regressions reported here was high with the F statistics in all cases highly significant at above $1 \%$ level. 
Figure 3: Imports Structure and Water Endowments (MENA), 1997

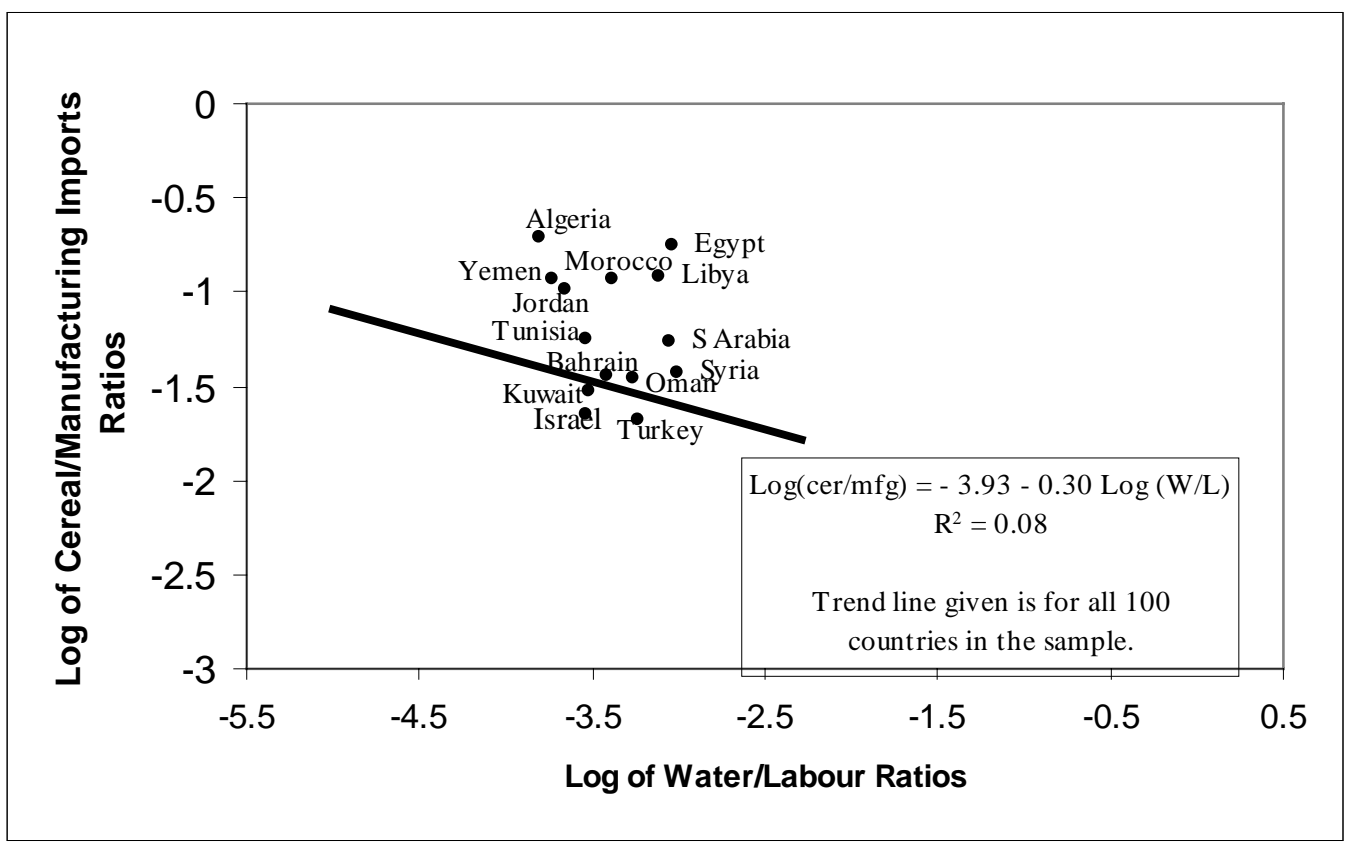

Note: this figure is based on equation 10 in Table 1. 


\section{Notes:}

${ }^{1}$ I am grateful to Tony Allan for his inspiring work on water and Massoud Karshenas for help and advice about the empirical methods used in the paper. The usual disclaimer applies.

${ }^{2}$ For populous, food-deficit oil exporters like Iran, this was closer to $12 \%$ (based on FAO Agrostat database and World Bank data, 2001).

3 Using an input-output framework, Leontief (1953) found out surprisingly that capital intensities of production for export industries in the USA in 1947 were below those in her importing industries. Implying that a capital-abundant country such as the USA was importing capital-intensive goods from the rest of the world, this counter-intuitive finding led to one of the most celebrated 'puzzles' in modern economics. Leontief, however, argued that US workers were roughly three times more productive than foreign workers. On the basis of this interpretation and multiplying the US aggregate labour force by a factor of three to produce 'comparable labour efficiency units', he argued that labour was in fact the relatively abundant input in the US. This led to him to argue that the USA exports labour-intensive goods, which is consistent with the H-O model (Krugman and Obstfeld, 1991: 75).

${ }^{4}$ Earle (2001) is an exception. Using the framework suggested by Bowen et al (1987), he used data from 63 countries to examine correlations between endowment of water compared to world supply and each country's share of grain production in world's total output. His study, however, failed to find support for the VW hypothesis.

${ }^{5}$ Annual internal renewable water resources refer to the average annual flow of rivers and recharge of groundwater generated from endogenous precipitation. Annual withdrawals refer to total water withdrawals, not counting evaporative losses from storage basins. Water withdrawals also include water from nonrenewable groundwater sources, river flows from other countries, and desalination plants in countries where that source is a significant part of all water withdrawals (World Resources Institute, 2000).

${ }^{6}$ It is worth reiterating that our study is not about determinants of food imports in general but about the influence of factor endowments on imports structure. This is why we would not necessarily expect high Rsquared values in a cross-country regression like those used here; although in our case the results are encouraging.

${ }^{7}$ An examination of the scatter plot for African countries included in the sample (not shown here) indicates a similar pattern: the great majority of observations appear above the trend line with the notable exception of South Africa and Zimbabwe - two more diversified economies and both exporters of grain. Despite this apparent similarity between African and MENA countries in this respect, it is plausible that the distortion in Africa is more the result of relative labour scarcity than water shortage.

${ }^{8}$ For all equations reported in Table 1 , the F statistic is very large and significant at the $1 \%$ level. 